\title{
Women and Medicine
}

\section{J Dacre}

Director of UCL Medical School, London, UK

This review is based on a presentation given by Professor Dacre at the RCPE Equal Opportunities in Medicine: Workforce Planning and Flexible Working Hot Topic Symposium held in Edinburgh on 4 October 2011.

\author{
Correspondence to J Dacre, \\ UCL Medical School, \\ Gower Street, \\ London, WCIE 6BT, UK
}

\begin{abstract}
To date, women have been a minority of the medical workforce. Recent data have shown that this situation will soon change, with the numbers of women in medical practice exceeding the numbers of men in the near future.This article outlines the history of women in medicine; it explores some of the data published by the Royal College of Physicians of London report Women and Medicine: The Future,' and other recent reports to highlight some key issues, in order to support sensible and appropriate policy decisions in relation to the changing demographic of the medical workforce.
\end{abstract}

tel. +44(0) 2076790894

e-mail j.dacre@ucl.ac.uk

DECLARATION OF INTERESTS Professor Dacre is the Chair of the RCP Women and Medicine Research Steering Group.

\section{A BRIEF HISTORY}

Historically, healthcare originated in the home, with women in many cultures taking on the responsibility for caring for the sick. With the creation of the Medical Royal Colleges around 500 years ago, this changed. The profession acquired status and became more attractive to ambitious men, in a society which did not recognise equal status for women.

In the late 1800 s, the suffragette movement encouraged an increase in the numbers of women wanting to work in the medical profession, but there were concerns expressed by many about the potential dangers. The anti-suffrage movement for example produced material that stated that menstruation made women too weak for higher education, and that study caused overwork and reduced a woman's reproductive capacity.' This opposition did not stop a significant number of pioneering women from attempting to qualify and work as doctors. One of the most well-known of these was Elizabeth Garrett Anderson (1836-1917). She tried to train at the Middlesex Hospital, but was forced to leave due to opposition. Anderson was one of a small number of women who passed the examination for the Society of Apothecaries. The Society did not realise that women were taking their qualifying examination however, and quickly put a stop to this loophole. In 1874, Anderson was a leading figure in the establishment of the London School of Medicine for Women, along with Sophia Jex Blake. Anderson retired in 1902 and became Mayor of Aldeburgh, the first female mayor in England.

Anderson's colleague, Sophia Jex Blake (1840-1912) trained at the University of Edinburgh but did not graduate. She eventually became licensed in Berne and Dublin. Blake was instrumental in setting up the London and Edinburgh Schools of Medicine for Women.

Scottish women were also among these medical pioneers. Elsie Inglis (1864-1917) was born in India, and trained in
Edinburgh. She set up the first Scottish Hospital for Women. During WWI, she went to Serbia, and was captured and repatriated. Perhaps the most intriguing of the Scottish medical pioneers was James (Miranda) Barry (cl795-1865), who graduated from the Medical School in Edinburgh in 1812 and became an army surgeon. She was promoted to Inspector General of Hospitals, and it was only on her death in 1865 that it was discovered she was a woman. She had been working as a man for 47 years; it seems not that uncommon for these ground-breaking women to masquerade as men in order to achieve their ambitions. This may be why it is difficult to establish precisely who the first women doctors were. Women were finally given the vote in the UK in 1918, and since then the numbers in the profession have been rising.

\section{THE CURRENT SITUATION}

In 2009, nearly 100 years later, the Royal College of Physicians of London (RCPL) published its research on women in medicine. It showed that since the 1960s, the number of men in the medical profession has doubled, and the number of women has increased tenfold. The study predicted that women would outnumber men in the medical profession by 2017 , or 2013 for general practioners. ${ }^{2}$ In 2007, the percentage of women entering medical school had stabilised at $56 \%$. The data showed that there were also ethnic differences in the numbers of applicants. In comparison to the numbers eligible to enter medical school, women are represented in proportion to their numbers in the population. The percentage of girls aged 15 taking secondary school (GCSE) exams in England in 2004 was around 41\%, and the number of university acceptances to study medicine and dentistry was approximately $40 \%$ in 2007 . The equivalent percentage of boys taking GCSEs was around $42 \%$ but only $27 \%$ of the university acceptances were for Caucasian males. Asian boys and girls are both overrepresented (around 3\% of the population and 12\% of acceptances). The data suggest that eligible Caucasian male applicants are choosing careers other than medicine. 
It will be interesting to see if the current economic crisis makes professional careers more attractive to young men.

In 2007 , the number of women already in the medical profession had risen significantly. The average number of female consultants was $28 \%$, however the number of women in training grades was $55 \%$. This suggests that large numbers of women will be eligible for consultant posts over the next few years.

These data have caused some concern in the profession, and have been discussed in the press. Some have suggested that the number of women now in the profession is 'worrying', ${ }^{3,4}$ The main concern seems to be the potential impact that an influx of women will have on working patterns. Many argue that these women are more likely to want to work part-time, and that this will cause staffing problems. Women in the profession are more liable to be working part-time already. In 2007, $48 \%$ of women in general practice were working part-time, and $35 \%$ in the medical specialties. This compares with only $16 \%$ in surgical specialties. There is evidence from the work of the $\mathrm{RCPL}^{2}$ that women are not evenly represented across the medical specialties. There are higher numbers of women in specialties where there is less acute and on-call work, which is easier to plan (such as the out-patient based specialties) and where there is less technical work. The least popular specialties for women include surgery and interventional radiology.

In 2008, the British Medical Association (BMA) published a report on women in academic medicine which also showed that women were not moving into the whole range of medical specialties in proportion to their numbers, and are not reaching the highest levels of academic attainment. Women were under-represented as clinical researchers, full-time academics and as heads of department. ${ }^{5}$ The authors suggested a change in culture was needed.The Medical Schools Council published a similar report, ${ }^{6}$ showing that there was attrition in the number of female clinical academics as their careers progressed, resulting in only II\% at professorial level and 36\% at lecturer level.

The women's movement has advocated complete equality for men and women in the workplace. In medicine, this will soon be achieved in pure numerical terms, with the proportion of women in the profession overall stabilising at just over $50 \%$. Although women are now well-represented at consultant level, they are not currently moving to the very top career levels. The RCPL research suggested that part of the reason for this was that women were not willing or able to invest in the traditional 'extra' responsibilities, such as overseas speaking, or national and international committee work. These activities are difficult to reconcile with family life, and society still expects women to be the main carers for children and the elderly. Some of this is just due to timing. With the larger numbers of women entering the profession, there are bound to be more female candidates for the top jobs eventually. The feminist debate about men and women and their different aspirations is still active. There are those who believe in bio-determinism, and that women are just not interested in the more senior positions, ${ }^{7,8}$ but there are also those who actively question this approach. ${ }^{91}$ The debate continues.

To support the trend of increasing numbers of women entering medicine, women need to be able to balance their working life with the needs of their families, and this means that there must be more opportunities for parttime working and more reliable and affordable childcare, as the Chief Medical Officer's report on women in medicine suggested in 2009." Women also need to be prepared to invest in the 'extra' responsibilities inherent in these roles, and to continue to show that they are committed and capable.

Over the last 500 years, there have been two female presidents of the RCPL, and none in Edinburgh or Glasgow. With the increasing numbers of women coming through the profession, is it time for a change?

The CMOs report made a series of recommendations directed specifically at medical organisations, and proposed leads for each one. Implementing these recommendations would bring about the necessary transformation change required to support the increasing numbers of women and make the best use of the workforce of the future.

\section{REFERENCES}

I Arguments against women's suffrage [Internet]. http://www.johndclare. net/Women I_ArgumentsAgainst.htm

2 Elston MA. Women and medicine: the future. London: Royal College of Physicians of London; 2009.

3 McKinstry M. Are there too many female medical graduates? Yes. BMJ 2008;336:748.http://dx.doi.org/ I 0. I I 36/bmj.39505.49I065.94

4 Dacre J. Are there too many female medical graduates? No. BM] 2008; 336:749. http://dx.doi.org/l0.I I36/bmj.39505.56670I.94

5 British Medical Association. Women in academic medicine. developing equality in governance and management for career progression. London: BMA; 2008. Available from: http://www.bma.org.uk/images/ Womenacademicmedicine_tcm4l-I78228.pdf

6 The Medical Schools Council. Women in clinical academia: attracting and developing the medical and dental workforce of the future. London: The Medical Schools Council; 2007. http://www.medschools.ac.uk/ AboutUs/Projects/Documents/Medical\%20Schools\%20Council\%20 Women\%20in\%20Clinical\%20Academia\%20Report2007.pdf

7 Cronin H.The battle of the sexes revisited. In: Grafen A, Ridley M, editors. Richard Dawkins: How a scientist changed the way we think. Reflections by scientists, writers and philosophers. Oxford: Oxford University Press; 2006. p.14-26.

8 Baron-Cohen S. The essential difference: men, women and the extreme male brain. London: Penguin/Basic Books; 2003.

9 Moran C. How to be a woman. London: Ebury Press; 2011.

I0 Walter N. Living dolls. The return of sexism. London:Virago Press; 2010.

II Deech R. Women doctors. Making a difference. Report of the Chair of the National Working group on Women in Medicine. London: Department of Health; 2009. Available from: http://www.renal.org/ pages/media/Flexible\%20trainees/baroness\%20deech\%20 report\%20for\%20CMO\%20oct\%202009.pdf 